\title{
北半球春季平流层最后增温过程及其年际和 年代际变化特征
}

\author{
胡景高 ${ }^{(1)}$ ，任荣彩 ${ }^{(2 *}$, 虞越越 ${ }^{(2)}$, 徐海明 ${ }^{(1)}$ \\ (1) 南京信息工程大学大气科学学院, 南京 210044 ; \\ (2) 中国科学院大气物理研究所大气科学和地球流体力学数值模拟国家重点实验室, 北京 100029 \\ * 联系人, E-mail: rrc@lasg.iap.ac.cn
}

收稿日期: 2013-01-07; 接受日期: 2013-06-04; 网络版发表日期: 2014-01-13

国家重点基础研究发展计划(编号: 2010CB428603 和 2010CB950400)和国家自然科学基金项目(批准号: 41275094)资助

\begin{abstract}
摘要
利用 1979 2010 年 NCEP-DOE 2 逐日再分析资料, 以北半球春季平流层极夜 急流核心纬带 $\left(65^{\circ} \sim 75^{\circ} \mathrm{N}\right)$ 纬向平均纬向风最后一次转为东风的日期定义为春季平流层 最后增温事件(SFW)的爆发日期, 研究发现, SFW 事件平均在 4 月中下旬发生, 且由平 流层高层向低层依次滞后, $10 \mathrm{hPa}$ 的 $\mathrm{SFW}$ 爆发平均超前 $50 \mathrm{hPa}$ 约 13 天; 爆发当日伴 随纬向风场时间变率和行星波辐合的最大值, 平流层环流实现由冬向夏的季节转换; 过去 32 年以来 SFW 的爆发早晚具有显著的年际变化, 最早的 SFW 事件发生在 3 月中 旬, 最晚的 SFW 事件在 5 月下旬才出现. 合成分析表明, SFW 爆发偏早(晚)年的春季, 纬向风场由西风向东风的转变更为快速(缓慢)，爆发前 5 天至爆发后 5 天, $30 \mathrm{hPa}$ 纬向 风减小约 $20 \mathrm{~m} \mathrm{~s}^{-1}\left(5 \mathrm{~m} \mathrm{~s}^{-1}\right)$, 伴随的平流层行星波活动也相对较强(弱); 表现在环流异 常场上, SFW 爆发前后平流层极区环流异常呈反(同)位相分布, 表明发生较早的 SFW 事件主要受波强迫驱动而伴随爆发性增温, 而发生较晚的 SFW 事件则更反映了极涡 的季节变化特征。无论 SFW 偏早还是偏晚年, 爆发后极区平流层与对流层温度异常之 间均呈反位相关系，反映了 SFW 爆发事件中的平流层-对流层动力耦合特征。另外，在 20 世纪 90 年代中期前后, SFW 爆发日期还存在明显的年代际转折, 90 年代中期之前 SFW 平均发生日期较之后约偏早 11 天; 与之相联系的是冬末、春初行星波活动在 90 年代中期之前偏强, 而在 90 年代中期之后有偏弱趋势.
\end{abstract}

北半球冬季热带外地区平流层与对流层之间存 在着很强的双向动力耦合, 这种耦合关系与北半球 环状模(NAM)、北极涛动 $(\mathrm{AO})$ 及平流层爆发性增温 (SSW) 等事件相联系, 伴随着这些事件强度和位相等
的变化, 平流层信号可以下传至对流层, 并对对流层 天气气候产生影响 (Thompson 和 Wallace, 1998; Baldwin 等, 2001, 2003; Limpasuvan 等, 2004; 李琳等, 2010). 平流层最后增温事件(SFW) 是指发生在春季,

中文引用格式: 胡景高, 任荣彩, 虞越越, 等. 2014. 北半球春季平流层最后增温过程及其年际和年代际变化特征. 中国科学: 地球科学, 44: 333-342 英文引用格式: Hu J G, Ren R C, Yu Y Y, et al. 2014. The boreal spring stratospheric final warming and its interannual and interdecadal variability. Science China: Earth Sciences, doi: 10.1007/s11430-013-4699-x 
因平流层极区快速增温而导致极浴最后崩溃，极夜 急流减弱消失从此转为东风气流的事件(Andrews 等, 1987), 它标志着平流层由冬季环流型转为夏季环流 型. 与一般的 SSW 事件发生的频率相比(北半球平均 每年 0.6 次(Charlton 和 Polvani, 2007)), 在南北半球, SFW 事件每年春天都会发生(Black 等, 2006). 已有研 究表明, 平流层大气环流由冬到夏的季节转换早于 对流层(陶诗言, 1964; 魏科等, 2007). 因此, 研究 SFW 过程中平流层大气环流的变化特征, 不仅有助 于理解极浴崩溃的物理过程, 以及其中的平流层-对 流层相互作用机理, 而且可能对把握对流层环流的 季节转换有重要意义.

关于 SFW 爆发的日期(SFWOD), Nash 等(1996) 定义 SFWOD 为沿极浴边缘(最大位浴梯度处)位浴等 值线的纬向风速小于某阈值 $\left(15.2 \mathrm{~m} \mathrm{~s}^{-1}\right)$ 的日期; Waugh 等(1999)总结了另外 2 种在等熵面上确定 SFWOD 的方法, 即指定 PV 等值线(Waugh 和 Randel, 1999; Zhou 等, 2000)或指定纬向风等值线(Waugh 等, 1999)所包含的面积. 然而, 魏科等(2007)发现, 在由 此所定义的 SFW 事件爆发之后, 平流层极区仍可能 维持一定大小的纬向西风, 说明该时间并不是极浴 彻底崩溃转化为夏季环流的时间. Black 等(2006, 2007a，2007b)定义等压面上平流层极夜急流核心区 的纬向风最后一次由西风转变为东风并不再恢复超 过某阈值(北半球和南半球分别为 5 和 $10 \mathrm{~m} \mathrm{~s}^{-1}$ ) 的日期 为 SFW 爆发的日期. Ayarzaguena 等(2009), Hardiman 等(2011)也采用了类似方法定义了 SFWOD.

有研究还表明, SFWOD 有明显的年际和年代际 变化, 20 世纪 80 年代中期至 90 年代末南北半球的冬 季极浴强度更强、极浴持续时间更长, SFW 偏晚 (Waugh 等, 1999; Waugh 和 Rong, 2002; Zhou 等, 2000; Labitzke 和 Naujokat, 2000; Haigh 和 Roscoe, 2009). Haigh 等(2009)利用南极站和 Halley 站探空资料得到 的 1957 2007 年的 SFW 时间序列表明, 南半球 SFWOD 在 2000 年之后有偏早的现象, 近些年北半球 SFW 事件是否有同样趋势值得关注.

关于 SFW 的气候效应, 有研究认为, 相对于大 气环流气候态演变而言, SFW 的爆发能加快平流层 的季节转换, 使得极区西风环流快速向东风环流转 变，同时也使对流层高纬地区的西风环流明显减小 (Black 等, 2006; 2007b), 但前人对 SFW 的研究往往 针对多年平均情形, 多集中于原始环流场, 对 SFW
爆发异常年份环流特征的分析较少, 亦较少关注环 流异常场的特征诊断. 本文将在前人研究的基础上 对 1979 2010 年北半球 SFW 爆发日期进行确定, 并 对异常年份 SFW 事件爆发前后的波动活动特征和环 流异常进行分析, 最后给出 SFW 年代际变化前后平 流层波动活动的差异.

\section{1 资料和方法}

选用 1979 2010 年 NCEP-DOE 2(Kanamttsu 等, 2002)逐日再分析资料，以及由逐日资料计算得到月 平均资料, 包括温度、纬向风和位势高度场等. 水平 分辨率为 $2.5^{\circ} \times 2.5^{\circ}$ 经纬格距，垂直方向从 $1000 \mathrm{hPa}$ 到 $10 \mathrm{hPa}$ 共 17 层. 在求取环流异常场时, 首先对 1979 2010 年各要素的多年气候平均场进行 31 天滑 动平均得到年循环场, 然后从原始场中去除年循环 场，从而得到历年逐日的要素异常场.

类似于 Black 等(2006，2007a)和魏科等(2007), 本文以北半球平流层极夜急流核心纬带 $\left(65^{\circ} \sim 75^{\circ} \mathrm{N}\right)$ 纬向平均纬向风最后一次转为东风并维持至当年秋 季(如果转为东风之后, 又恢复至西风, 则西风大小 不超过 $5 \mathrm{~m} \mathrm{~s}^{-1}$, 且西风维持不超过 5 天)的日期, 定义 为该年 SFW 的爆发日期. 考虑到极夜急流核心区纬 向西风转为东风之后会恢复至较低值的西风, 并且 在有些年份会持续较长时间, 如 1999 年这样较低值 的西风持续超过一个月，因此，本文限制“恢复的西 风”维持时间不超过 5 天, 这与以往研究(Black 等, 2006; 魏科等, 2007)有所不同, 在 1979 2010 年共 32 年中有 6 年会出现这样的差异, 这将使本文 SFW 平 均爆发日期有所偏晚. 文中将对 SFW 爆发前后环流 异常和波动特征进行合成分析，合成方法是对 SFW 爆发当日前后各一个月的要素场进行多年平均.

\section{1979 2010 年北半球 SFW 爆发日期的 确定}

图 1(a)给出了 1979 2010 年平流层 10 50 hPa SFWOD 时间序列. 由图 1 可知, 北半球平流层 SFW 主要发生在 3 月中下旬至 5 月中下旬, 前后相差约 2 个月; 且年际变化明显，各层次标准差达 15.2 19.2 天; 10 50 hPa SFW 平均爆发日期分别为 4 月 15 日, 4 月 16 日, 4 月 20 日和 4 月 28 日, 表明平流层高层极 
浴崩溃依次早于低层(图 1(a)). 根据平流层各层极浴 崩溃日期的分布，选择 $30 \mathrm{hPa}$ 的 SFWOD 来代表平流 层极浴崩溃的平均日期, 由图 1(b) 可见, 从 1979 2010 年, SFWOD 有显著(超过 0.05 显著水平) 的偏晚趋势(标准化时间序列与线性拟合时间序列的 相关系数为 0.407), 这与前人(Labitzke 和 Naujokat, 2000; Waugh 和 Rong, 2002; 魏科等, 2007)用不同方 法定义 SFWOD 所得的结论一致, 说明对于不同的极 浴崩溃时间的划分标准, 20 世纪 70 年代末以来 SFWOD 的偏晚趋势是确定的. 图 1(a)所给出的 SFWOD 较以往工作(Black 等, 2006; 魏科等, 2007) 平均约偏晚 5 10 天, 这一方面可能是由于本文所依 据的资料时间序列已延长至 2010 年, 使 SFWOD 的 偏晚趋势更明显, 另一方面是因为本文在定义
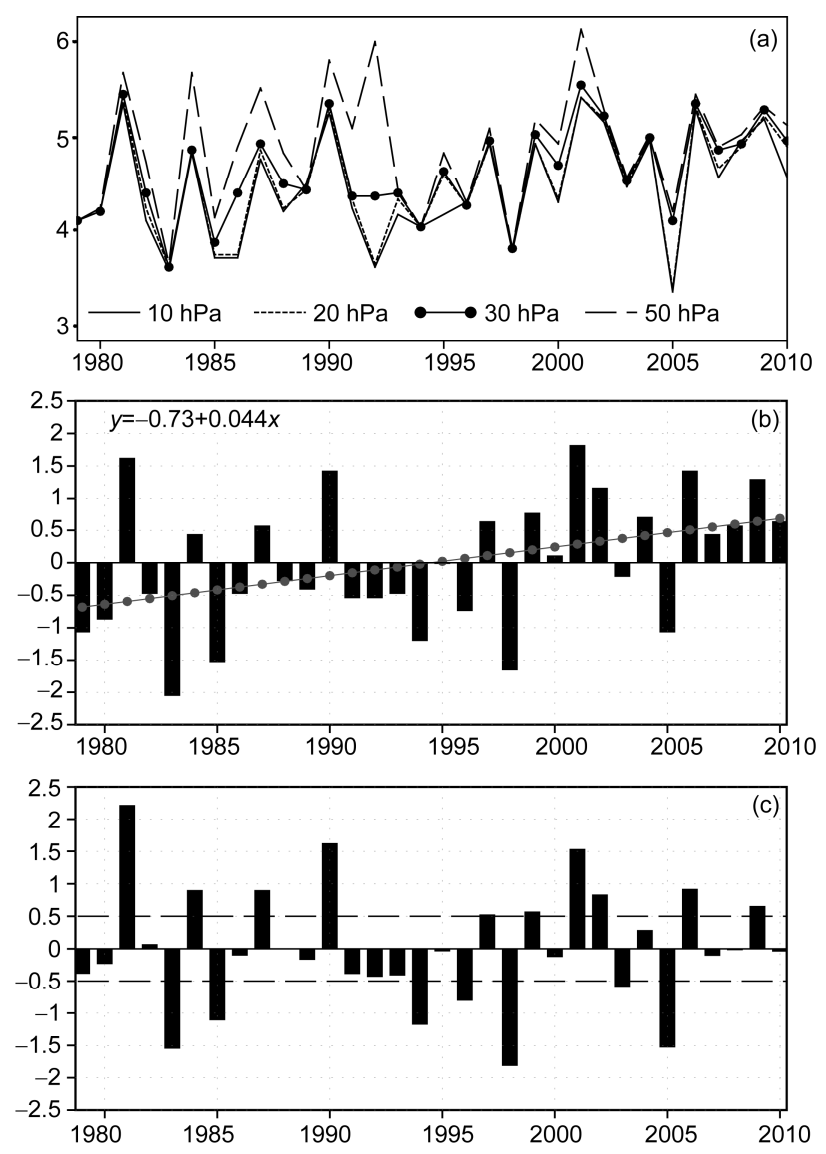

图 1 1979 2010 年北半球 10 50 hPa SFW 爆发时间序列(a), 30 hPa SFW 爆发时间的标准化序列(b)及去线性趋势后的 序列(c)

带点实线为线性趋势线
SFWOD 时, 附加了 SFW 爆发后西风出现的时间需 不超过 5 天的条件. 关于与 SFWOD 年代际偏晚趋势 有关的分析, 将在后面的第 4 部分详细阐述.

去除 SFWOD 的年代际线性趋势后, 定义 SFWOD 超过 \pm 0.5 个标准差的年份为 SFW 爆发日期 异常偏早或偏晚年份, 选取 1983，1985，1994，1996, 1998,2003 和 2005 年共 7 个典型偏早年和 1981,1984 , $1987,1990,2001,2002,2006$ 和 2009 年共 8 个典型偏 晚年进行合成分析(图 1(c)), 所选异常偏早年 SFW 平 均爆发日期为 3 月 28 日, 异常偏晚年为 5 月 6 日.

\section{SFW 爆发异常偏早、偏晚年环流特征} 对比

Hardiman 等(2011)利用 ERA-Interim 月平均资料 的研究表明, 在北半球 $81 \%$ (使用逐日资料时为 $72 \%$ ) 的 SFW 事件首先发生在 $10 \mathrm{hPa}$ 附近, 当 SFW 爆发之 后, 平流层 $10 \mathrm{hPa}$ 高纬度地区转变为东风, 对流层行 星波不能穿过 $10 \mathrm{hPa}$ 到达更高层次, 因此 $10 \mathrm{hPa}$ 以 上和以下的平流层 SFW 事件有着不同的物理基础和 环流特征, 本文以下对环流和波动的分析主要集中 在 $10 \mathrm{hPa}$ 以下的平流层和对流层.

\section{1 纬向风场演变}

图 2 给出了 SFW 爆发异常偏早和异常偏晚年份, 在爆发前后 60 天内平流层 10 50 hPa $65^{\circ} \sim 75^{\circ} \mathrm{N}$ 纬向 平均纬向风及其时间变化率(UT) 的平均时间演变. 由图 2(a) 可见, 对于 SFW 爆发偏早年, 平流层各层纬 向风场的平均演变可分为 3 个主要阶段: 第一阶段从 爆发前一个月至爆发前 8 天, 为纬向风缓慢减弱阶段, 在该阶段内纬向风速累计减弱约 7 15 $\mathrm{m} \mathrm{s}^{-1}$, 减弱幅 度高层依次大于低层; 第二阶段为爆发前 8 天至爆发 后 3 5 天, 为纬向风快速减弱阶段, 10 15 天内纬向 风速减弱可达 $20 \sim 30 \mathrm{~m} \mathrm{~s}^{-1}$; 第三个阶段为爆发后 5 30 天, 表现为一个缓慢的恢复阶段, 东风风速减 弱维持. 体现在纬向风时间变化率(UT)上, 在爆发前 一个月至爆发前 8 天, UT 表现为正负交替振荡, 大小 不超过 $2 \mathrm{~m} \mathrm{~s}^{-1} \mathrm{~d}^{-1}$, 可能反映了 $\mathrm{SFW}$ 懪发前较频繁的 波动活动; 在爆发前 8 天至爆发后 3 5 天, 各层 UT 量值均较大并在 SFW 爆发当天达负的最大值, 高层 至低层约为 $-5 \sim-3 \mathrm{~m} \mathrm{~s}^{-1} \mathrm{~d}^{-1}$, 说明 SFW 事件的爆发对 

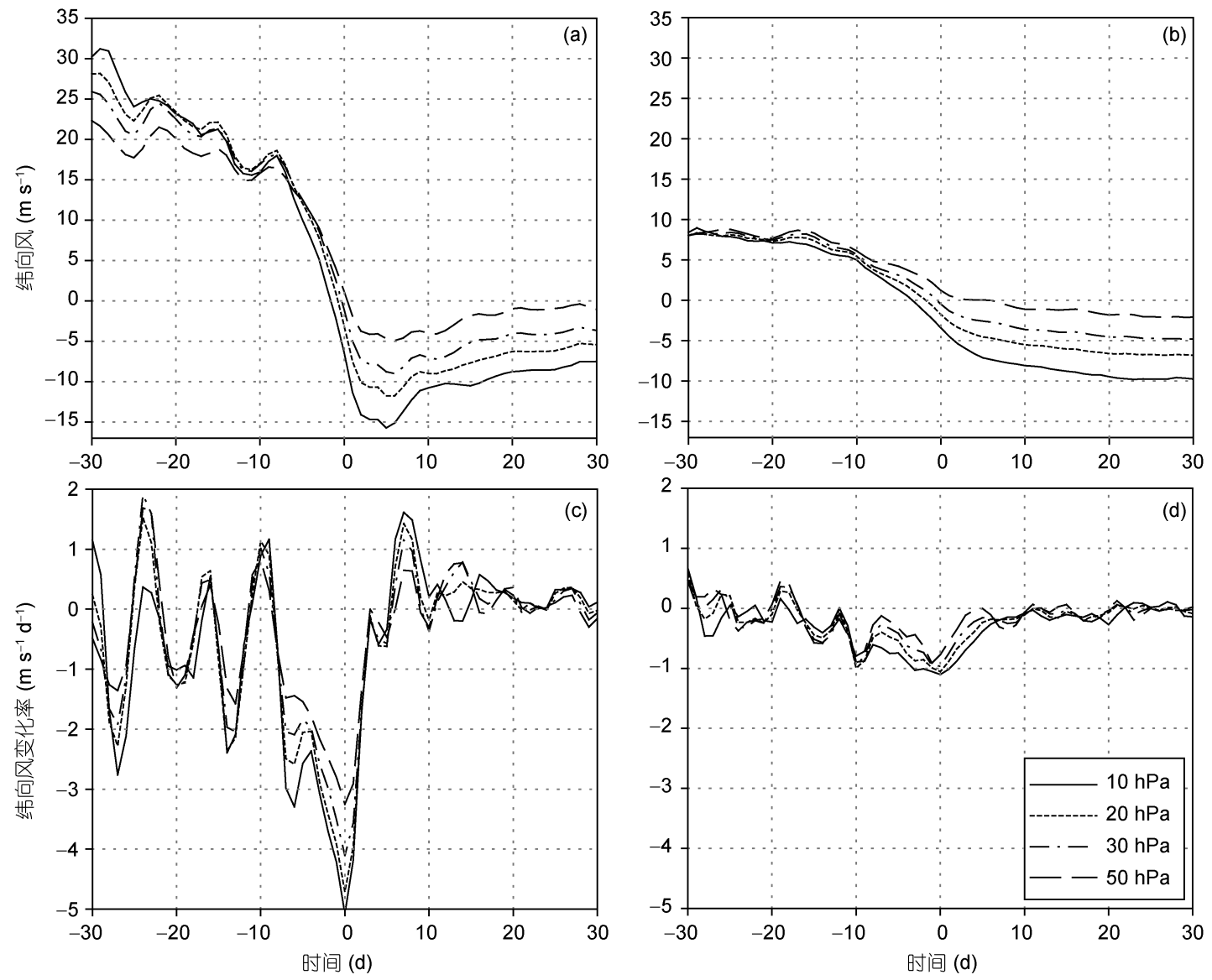

图 $2 \mathrm{SFW}$ 爆发前后 60 天内平流层 $10 \sim 50 \mathrm{hPa} 65^{\circ} \sim 75^{\circ} \mathrm{N}$ 纬向平均纬向风及其时间变化率的时间演变

(a)和(c) SFW 偏早年; (b)和(d) SFW 偏晚年. 第 0 天表示 SFW 爆发当日, 下同

纬向环流由西风向东风转换的加速作用; 从爆发后 5 天开始, UT 以正值为主, 反映了纬向环流的缓慢恢 复(图 2(c)).

与偏早年不同, 在 SFW 爆发异常偏晚年, 爆发 前后平流层纬向风呈现一致的缓慢减弱趋势, 减弱 幅度从低层至高层约为 10 20 $\mathrm{m} \mathrm{s}^{-1}$ (图 2(b)). 对应的 $\mathrm{UT}$ 量值较偏早年明显偏小, 最大值仅为 $-1 \mathrm{~m} \mathrm{~s}^{-1} \mathrm{~d}^{-1}$, 也出现在爆发当天; SFW 爆发 10 天以后, 对应东风 风速的持续(图 2(b)), UT 的量值接近于 0 (图 2(d)). 由 图 2(a)和(b)还可以发现, SFW 的爆发(纬向风速达到 0)总是平流层高层依次领先于低层, 但高层与低层之 间爆发日期的时间间隔在偏早年明显小于偏晚年. 另外, 对比图 2(a)和(b)中纬向风速的强度还可知, 在 SFW 爆发前, 极浴强度在偏早年明显强于偏晚年; 在 SFW 爆发 20 天之后，偏早年的东风环流相对于偏 晚年又较弱.

\section{2 波动活动的演变}

平流层 SFW 的爆发受辐射非绝热加热和波动活 动的影响. Eliassen-Palm(EP)通量不仅可以表征波动 活动特征，而且可用于诊断波流相互作用，准地转近 似条件下，球坐标系中 EP 通量和欧拉平均方程分别 为(Andrews 等, 1987)

$$
\begin{gathered}
F_{\phi}=\rho a \cos \phi\left(-\overline{v^{\prime} u^{\prime}}\right), \\
F_{z}=\rho a f \cos \phi \overline{v^{\prime} \theta^{\prime}}\left(\frac{\partial \bar{\theta}}{\partial z}\right)^{-1}, \\
\nabla \cdot \vec{F}=(a \cos \phi)^{-1} \frac{\partial}{\partial \phi}\left(F_{\phi} \cos \phi\right)+\frac{\partial F_{z}}{\partial z}, \\
\frac{\partial \bar{u}}{\partial t}-f \bar{v}^{*}-\overline{\mathrm{X}}=\frac{\nabla \cdot \vec{F}}{\rho a \cos \phi}=\mathrm{DIVF},
\end{gathered}
$$

式中, $\rho, a$ 和 $\phi$ 分别为空气密度、地球半径和纬度, $\theta$ 
和 $f$ 表示位温和地转参数, “-”和“””表示纬向平均和纬 向偏差, $F_{\phi}$ 为 $\mathrm{EP}$ 通量的水平分量, 表示浴动动量通 量部分, $F_{z}$ 为 $\mathrm{EP}$ 通量的垂直分量, 表示浴动热输送 部分, $\nabla \cdot \vec{F}$ 为 $\mathrm{EP}$ 通量的散度, $\vec{v}^{*}$ 和 $\overline{\mathrm{X}}$ 分别为剩余环 流项和摩擦耗散项, DIVF 为波驱项, 下文中的 EP 通 量散度即指波驱项. 可见, 当波动作用使 EP 通量辐 合时, 纬向基本气流将减速, EP 通量辐散时, 纬向基 本气流将加速.

图 3 给出了 $\mathrm{SFW}$ 爆发前后 60 天内, $65^{\circ} \sim 75^{\circ} \mathrm{N}$ 纬 带内行星波(1 3 波)EP 通量向上分量及其通量散度 (DIVF) 的演变. 由图 3(a) 可知, 在 SFW 爆发异常偏早 年, 爆发之前波动活动很强, 几次主要的峰值分别出 现在爆发前 27 天, 17 天和爆发当日; 在 SFW 爆发之 后, 波动活动迅速减弱(图 3(a)); SFW 爆发异常偏晚 年中波动的活动强度相对很弱, 且在爆发前随时间 缓慢递减(图 3(b)). EP 通量散度与纬向风场的时间变 化率具有很好的对应关系, EP 通量的辐合最大值出
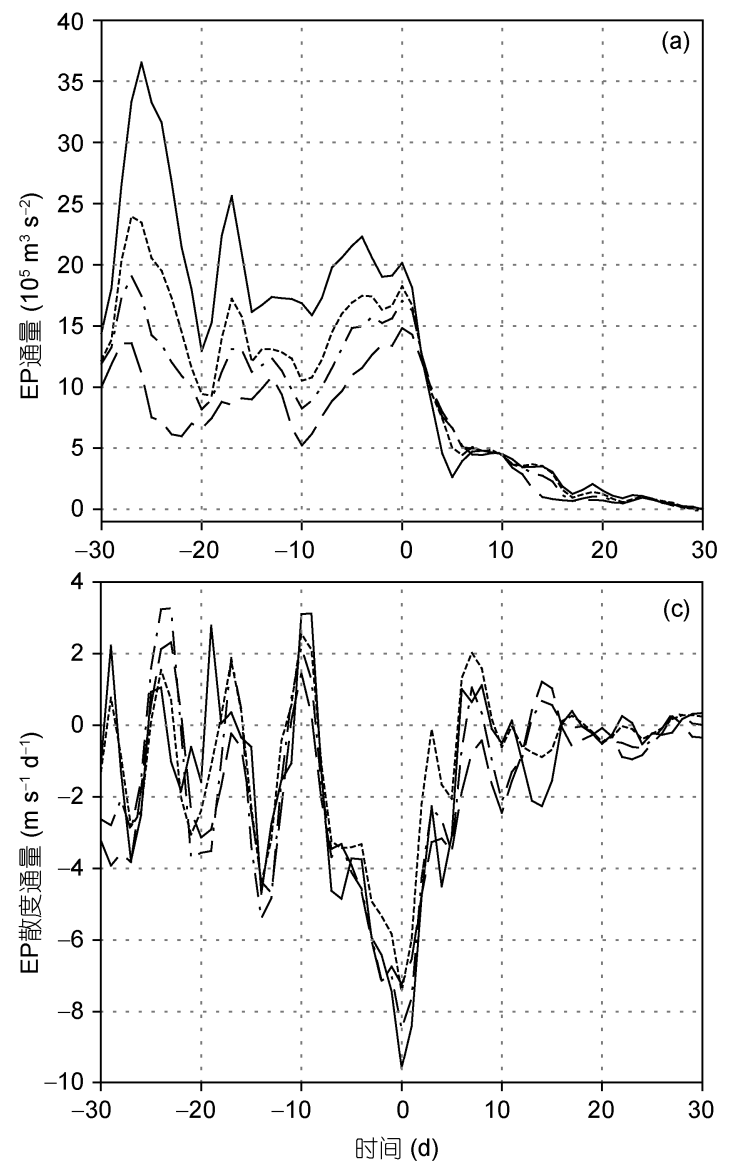

(c)

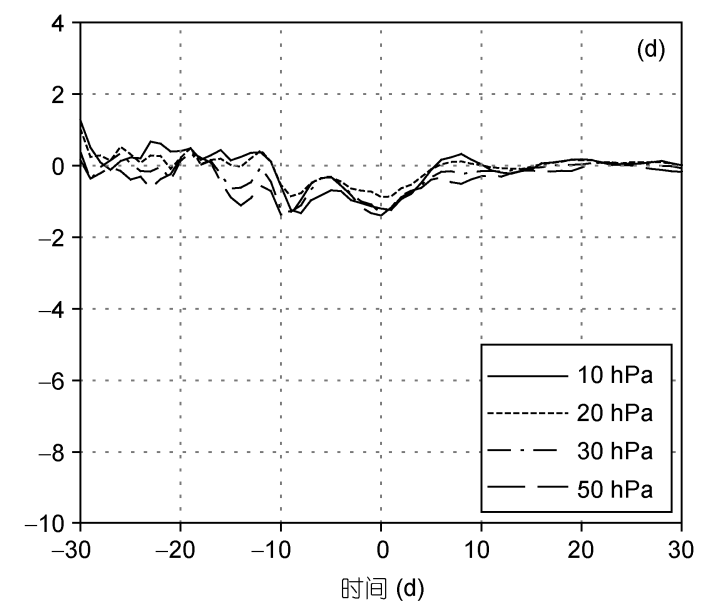

图 3 SFW 爆发前后 60 天内行星波(1 3 波)EP 通量的向上分量 $((a),(b))$ 及其通量散度 $((c),(d))$ 的时间演变
现在 SFW 爆发当天, 对于异常偏早年, EP 通量散度 的量值约为 UT 量值的两倍(图 3(c) 和图 2(c)), 而在异 常偏晚年, EP 通量散度与 UT 的量值近乎相当(图 3(d) 和图 2(d)).

由以上分析不难看出, 异常偏早年与异常偏晚 年中 SFW 事件的平均特征截然不同. 在 SFW 事件偏 早年, 由对流层上传至平流层的波动的活动很强, 并 在平流层极区出现较强辐合, 平流层极夜急流因此 可在数天内转变成东风环流, SFW 事件主要受波强 迫驱动而伴随爆发性增温; 在 SFW 事件偏晚年, 平 流层波动活动相对很弱, 平流层极夜急流转为东风 的过程相对缓慢, 在此转换过程中, 平流层经向温度 梯度的反转受辐射非绝热加热的强迫作用, 更多的 反映了极浴的季节变化特征, 这与魏科等(2007)的结 论是一致的, 而 Waugh 等(2002)由于选择了不同的 SFWOD 的划分标准, 主要分析了极涡崩溃过程的初 始阶段(平流层极区仍维持一定大小的西风), 得出了

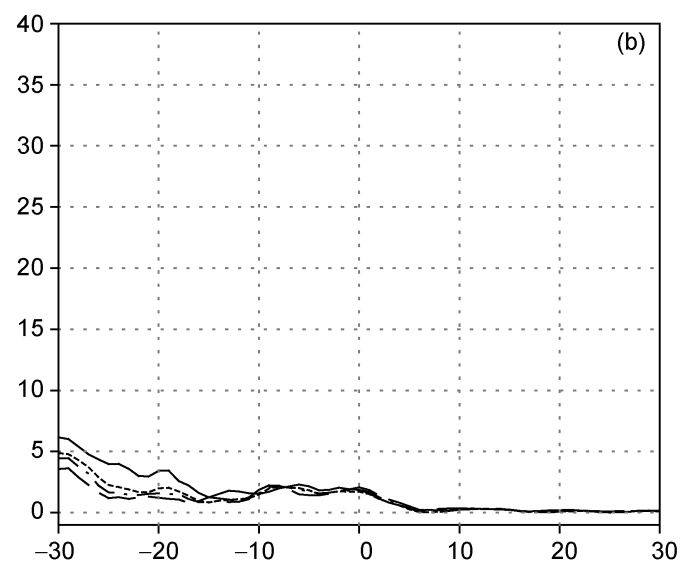


SFW 爆发偏早和偏晚年都有较强波动的结论.

\section{3 环流异常场的演变特征}

在对比分析 SFW 爆发异常年份的环流异常特征 之前, 我们首先给出了 1979 2010 年所有年份平均的, SFW 爆发前后高纬度纬向风异常、温度异常以及位 势高度异常场的演变(图 4). 在 SFW 爆发前后, 极区 环流异常场均出现位相翻转. 具体地, 纬向平均纬向 风的在爆发前整层皆为西风异常, 爆发后转为东风 异常, 且东风异常在爆发后一候内有明显增强, 之后 东风风速逐渐减小(图 4(a)); 高度异常场与纬向风异 常类似, SFW 爆发前极区为负位势高度异常所主导, 在爆发后转为正位势高度异常, 并且正异常在爆发 后一候内增加趋势明显, 之后正位势高度异常逐渐 减弱(图 4(c)). 在温度异常场上, SFW 爆发前从 700 $\mathrm{hPa}$ 到 $30 \mathrm{hPa}$ 均为负温度异常所控制, SFW 爆发后转 为正异常场; 在爆发之前 27 天, 平流层高层 10 20 $\mathrm{hPa}$ 已经出现温度正异常, 正异常随时间逐渐增大直 至爆发后一候, 反映了高层 SFW 爆发依次领先于低 层的特征; 与此特征相一致, SFW 爆发前后平流层的 正负温度异常均呈现显著的随时间向下传播特征(图 4(b)), 平均而言, 与 SFW 爆发有关的温度异常由高 层 $10 \mathrm{hPa}$ 传播到平流层低层 $100 \mathrm{hPa}$ 约需 30 天左右.

图 5 给出了异常偏早和异常偏晚年 SFW 爆发前 后环流异常场的时间演变. 由图 5(a), (c)和(e)可见, 偏早年时, SFW 爆发前后平流层极区环流异常的演 变特征与图 4 中的平均状态类似, 主要表现为纬向风 和高度异常场在爆发前后有明显的反位相特征, 温 度异常超前于纬向风和高度异常, 且温度异常有明 显的下传特征; 不同的是, 与平均状态相比, SFW 爆 发前后各异常场的中心值都有明显的增强. 由图 5(b), (d)和(f)可知, 在偏晚年 SFW 爆发前后, 平流层极区 环流异常并不存在位相翻转, 除第 18 天之后的小片 区域外, 平流层极区持续为西风异常、负位势高度和 负温度异常所控制, 纬向风正异常中心和位势高度 负异常中心位于 SFW 爆发前 15 天的 10 20 hPa, 温 度负异常中心位于 SFW 爆发前 30 天的 $10 \sim 20 \mathrm{hPa}$, 超前于纬向风和位势高度的异常中心. 这说明对于 SFW 爆发偏晚年, 平流层环流异常的性质并未发生 转变. 另外, 由图 5(c)和(d)不难发现, 无论偏早还是 偏晚年, SFW 爆发后极区平流层的温度异常与对流 层总呈反位相关系, 这种反位相关系与 Ren 等(2007)
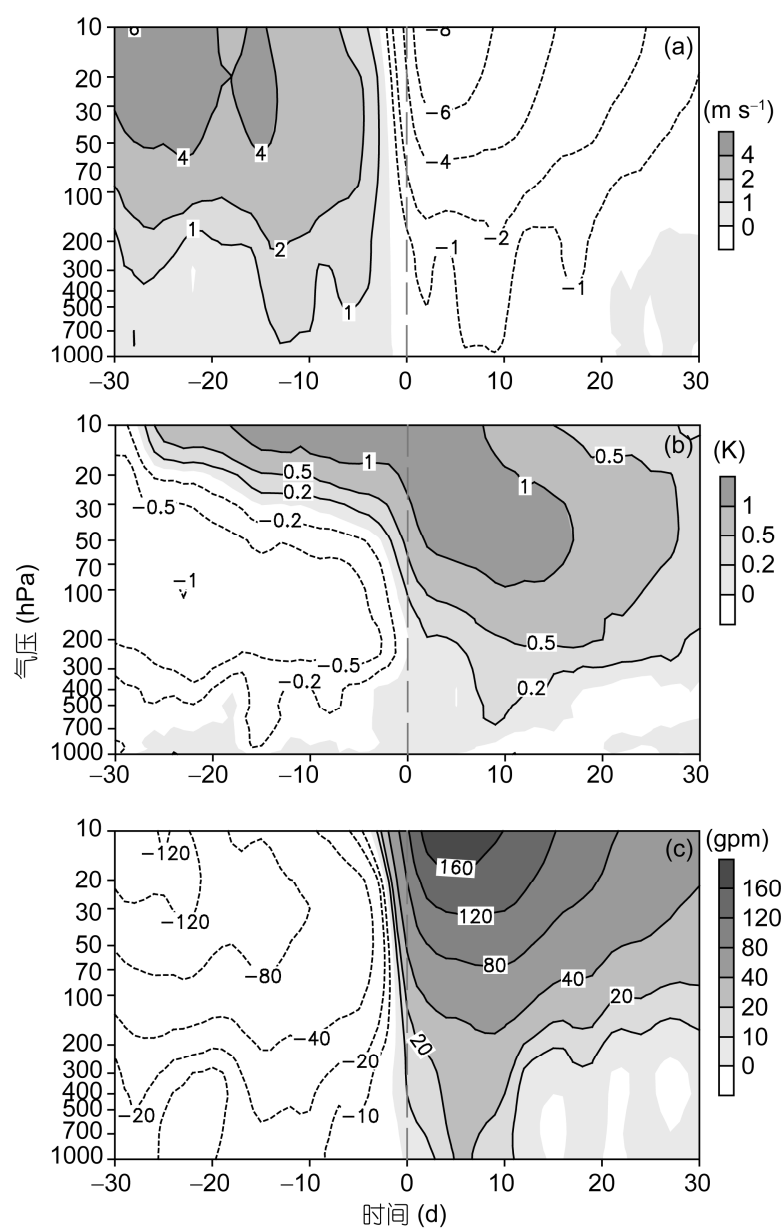

图 4 1979 2010 年 SFW 爆发前后环流异常场的演变

(a) $65^{\circ} \sim 75^{\circ} \mathrm{N}$ 纬向平均纬向风异常; (b) 极区 $60^{\circ} \sim 90^{\circ} \mathrm{N}$ 平均温度异 常; (c) 极区 $70^{\circ} \sim 90^{\circ} \mathrm{N}$ 平均位势高度异常

和 Cai 等(2007)所指出的冬季极浴振荡事件过程极区 平流层与对流层温度异常反位相关系非常类似，表 明 SFW 事件的爆发也同样伴随着显著的平流层-对流 层动力耦合.

\section{SFW 爆发日期的年代际变化及其可能原因}

前文分析表明, SFWOD 在 20 世纪 90 年代中期 前后, 存在明显的年代际转折, 转折之后 SFW 爆发 日期较转折之前明显偏晚(图 1(b))。为了说明 SFWOD 年代际变化可能的原因, 类似于前面的合成 分析, 将 1979 2010 年分为 1980 1994 年和 1996 2010 年两组, 给出了 1980 1994 年和 1996 2010 年 $10 \sim 50 \mathrm{hPa}$ 各层 $55^{\circ} \sim 75^{\circ} \mathrm{N}$ 平均 $\mathrm{EP}$ 通量垂直分量距平 随时间的变化(图 6, 其中 10 12 月分别为 1979 1993 

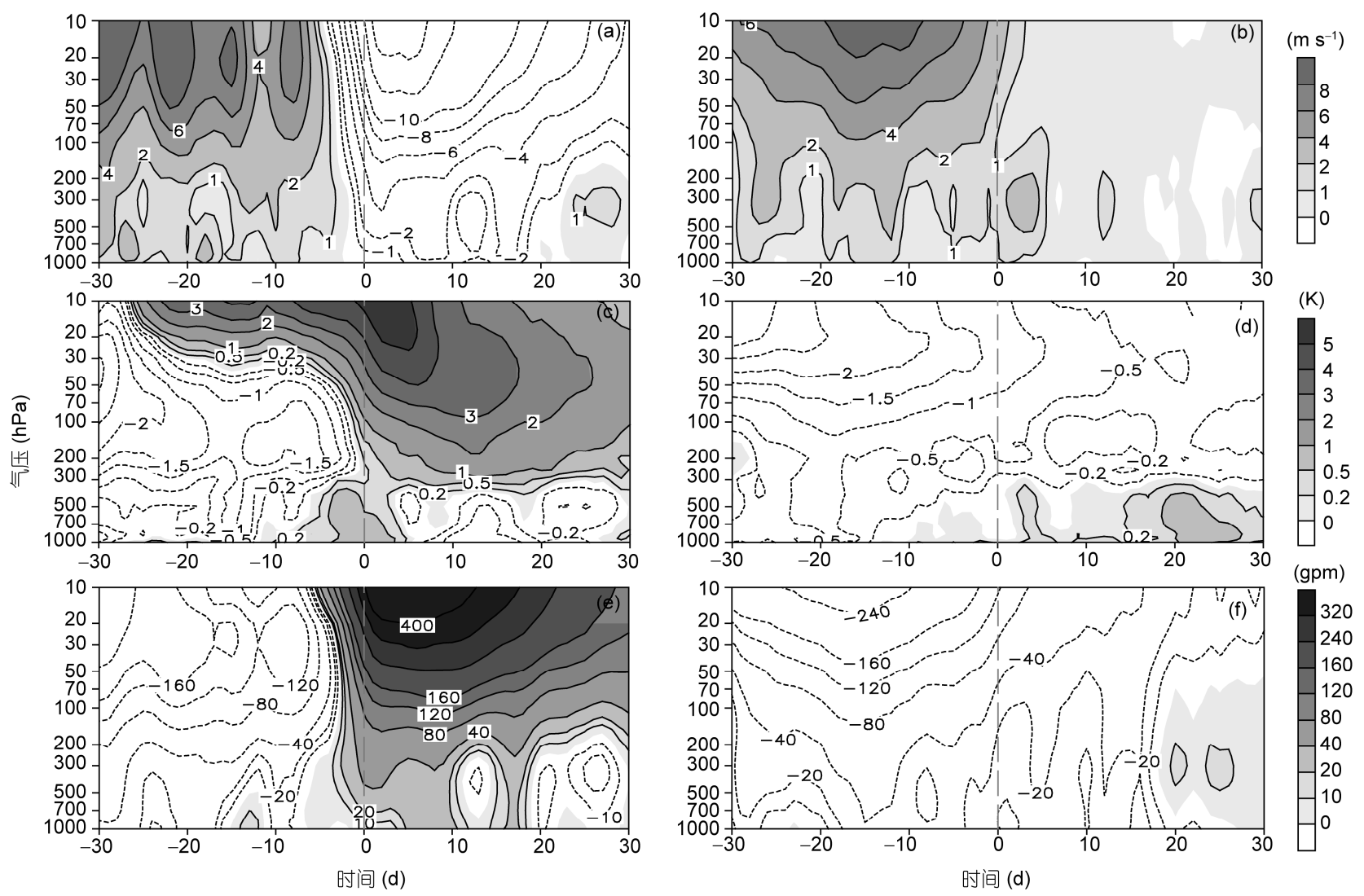

图 5 SFW 异常偏早(左)、偏晚年(右)平均环流异常在爆发前后 60 天时间的演变 (a), (b) $65^{\circ} \sim 75^{\circ} \mathrm{N}$ 纬向平均纬向风异常; (c), (d) 极区 $60^{\circ} \sim 90^{\circ} \mathrm{N}$ 平均温度异常; (e), (f) 极区 $70^{\circ} \sim 90^{\circ} \mathrm{N}$ 平均位势高度异常
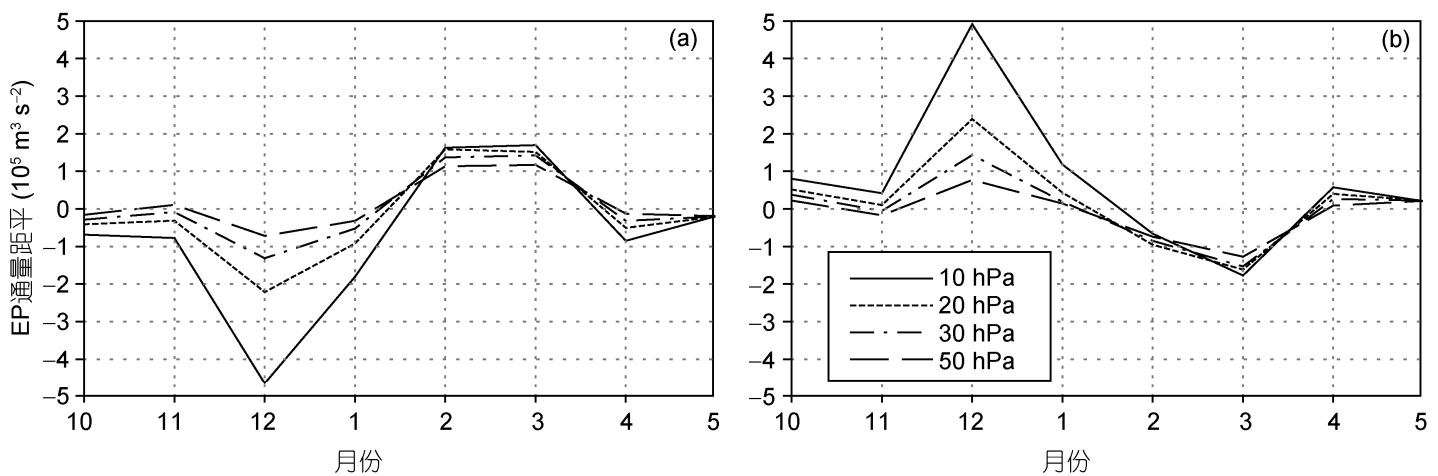

图 $61980 \sim 1994$ 年(a)和 1996 2010 年(b)10 50 hPa 各层 $55^{\circ} \sim 75^{\circ} \mathrm{N}$ 平均 EP 通量垂直分量距平随时间的变化

年和 1995 2009 年平均). 由图 6 可知，两个阶段间波 动活动的主要差异出现在 12 月, 2 月和 3 月. 在年代 际转折前, 冬季 12 月份平流层的波动通量小于转折 之后, 但在 2 3 月为正异常, 明显强于转折之后的年 份, 说明初冬和暮冬至初春, 平流层高纬度的波动活 动特征不尽相同, 这种年代际转折后初冬波动增加
和暮冬至初春波动减少的变化与 $\mathrm{Hu}$ 等(2002, 2003) 认为的 20 世纪 80 年代以来的平流层波动活动的变化 相一致. 图 7 为 1980 1994 年和 1996 2010 年两个阶 段, 3 月份 $\mathrm{EP}$ 通量距平及其散度(DIVF)距平的纬度高度分布. 可见两个时段 EP 通量的异常主要表现为 垂直分量的异常, 在年代际转折之前, 高纬度平流层 
整层为 $\mathrm{EP}$ 通量垂直分量的正距平和辐合异常, 且大 值区位于平流层中层 10 30 hPa. 这种波动的辐合有 利于平流层极区纬向基本气流减速, 或由西风转变 为东风, 使 SFW 爆发偏早(图 7(a)); 在年代际转折之 后(图 7(b)), EP 通量为向下异常, 且在平流层极区为 辐散异常, 有利于极区西风维持到 4, 5 月份, 此时 EP 通量的量值已经很小, 因此 SFW 爆发偏迟, 主要受 辐射非绝热加热的影响. 这种波动活动的年代际变 化与前文关于异常年份波动活动的合成结果相一致.

关于北半球 SFW 爆发偏迟趋势的外强迫原因, $\mathrm{Hu}$ 等(2003)认为 20 世纪 80 年代以来北极地区平流 层臭氧的减少导致平流层波动活动的减弱, 将导致 平流层增暖事件的异常. 事实上平流层极区臭氧含 量的减少, 可减少平流层大气对太阳辐射的吸收, 使 平流层极区温度降低, 有利于维持较大的温度经向 梯度, 从而造成纬向基本气流的自然季节过渡减缓. 另一方面，臭氧减少有利于 SFW 爆发前期副极地地 区西风急流变强, 从而有利于对流层行星波向低纬 地区折射, 使得对流层高纬地区及由对流层上传至 平流层的波动活动减弱 $(\mathrm{Hu}$ 等, 2003), 进而减小了波 动辐合对纬向基本气流的减速作用. Shindell 等(1999, 2001)的一系列模拟工作指出, 温室气体是引起 NAM 指数上升趋势的最重要因素. 最近 Ren 等(2012)用 FGOALS-s2 气候系统模式对冬季平流层环流变化模 拟结果的分析表明, 在更长时间尺度(2006 2100 年) 温室气体增加的情景下, 平流层极区温度将持续降 低, 极浴强度将继续偏强, 而行星波活动并无减弱趋
势; 较行星波活动变化趋势而言, 极浴的长期加强趋 势与温室气体引起的平流层辐射冷却联系更加紧密. 但 Ren 等(2012)同时指出，在年际和年代际时间尺度 上行星波活动与极浴的变化仍然密切相关. 这与本 文关于 SFW 年代际变化与行星波活动的关系的分析 结果是一致的.

\section{5 讨论与结论}

本文以北半球春季平流层极夜急流核心纬带 $\left(65^{\circ} \sim 75^{\circ} \mathrm{N}\right)$ 纬向平均纬向风最后一次转为东风(如果 转为东风之后, 又恢复至西风, 则西风大小不超过 5 $\mathrm{m} \mathrm{s}^{-1}$, 且西风维持不超过 5 天)的日期定义为春季平 流层最后增温事件(SFW)的爆发日期, 在此基础上对 SFW 爆发前后的环流异常和波动活动特征进行了分 析, 得到的主要结论如下:

(1) 北半球 SFW 事件主要发生在 3 月中下旬至 5 月中下旬，年际变化很大; SFW 爆发日期由平流层高 层向低层依次滞后, $10 \mathrm{hPa}$ 的 SFW 爆发平均超前 50 $\mathrm{hPa}$ 约 13 天; 过去 32 年来平流层 SFW 爆发日期还表 现有显著的年代际偏晚趋势, 20 世纪 90 年代中期之前 SFW 爆发日期平均比 90 年代中期之后约偏早 11 天.

(2) 在 SFW 年代际偏晚趋势之外, 分析 SFW 爆 发偏早、偏晚年爆发前后环流演变特征发现，偏早(晚) 年, SFW 爆发前极浴强度偏强(弱), 爆发期间纬向风 场由西风环流快速(缓慢)转变为东风环流，平流层极

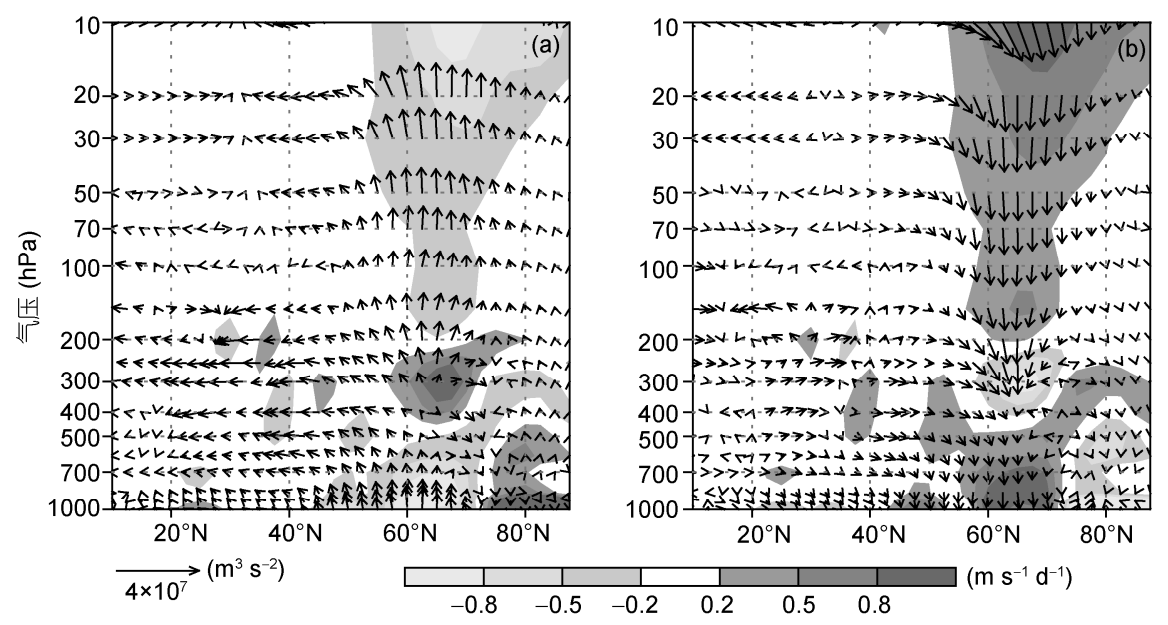

图 7 1980 1994 年(a)和 1996 2010 年(b)平均 3 月 EP 通量距平及其散度(DIVF)距平的纬度-高度分布 箭矢, 垂直分量扩大了 100 倍 
区的波动活动偏强(弱). 爆发当日纬向风场时间变化 率和行星波的辐合均达最大值, 但偏早年明显强于 偏晚年. 发生较早的 SFW 事件主要受波驱动而伴随 爆发性增温, 而发生较晚的 SFW 事件则更反映了极 浴的季节变化特征.

（3）偏早年 SFW 爆发前后平流层极区环流异常 特征与多年平均类似, 爆发前后环流异常符号反转, 反位相特征明显. 与平流层高层 SFW 爆发领先于低 层的特征相一致, 平流层温度异常场在 SFW 爆发前 后呈现明显下传特征. 偏晚年 SFW 爆发前后平流层 极区环流异常不存在反位相关系, 纬向风维持为西 风异常, 温度和位势高度异常场为负异常. 此外, 无 论偏早年还是偏晚年 SFW 爆发后极区平流层与对流 层的温度异常始终呈反位相关系, 表明 SFW 事件的 爆发伴随着显著的平流层-对流层动力耦合.
(4) SFW 事件的年代际转折前后平流层极区波 动特征有明显不同, 20 世纪 90 年代中期的年代际转 折以前, 春季 3 月由对流层上传至平流层的 $\mathrm{EP}$ 通量 异常增多, 并且在平流层极区异常辐合, 使得平流层 极区纬向基本气流减速, SFW 爆发偏早; 年代际转折 以后, EP 通量为负异常, 并在平流层极区异常辐散, 使 SFW 爆发偏迟. 说明在年际和年代际尺度上行星 波活动与 SFW 事件密切相关.

平流层最后增温事件是发生在春季热带外平流 层最重要的事件之一, 是平流层由冬到夏季节转换 的标志, 偏早年与偏晚年 SFW 事件有着不同的动力 和热力性质, 且异常年份 SFW 爆发之后对流层极区 有着不同的环流特征，平流层最后增温事件可能对 对流层季节过渡阶段的天气气候事件产生重要影响, 对把握对流层环流的季节转换有重要意义.

\section{参考文献}

李琳, 李崇银, 谭言科, 等. 2010. 平流层爆发性增温对中国天气气候的影响及其在 ENSO 影响中的作用. 地球物理学报, 53: 1529-1542 陶诗言. 1964. 平流层大气环流及太阳活动对大气环流的影响的研究. 北京: 科学出版社. 27-45

魏科, 陈文, 黄荣辉. 2007. 北半球平流层极浴崩溃过程的动力诊断分析. 中国科学 D 辑: 地球科学, 37: 1110-1119

Andrews D G, Holton J R, Leovy C B. 1987. Middle Atmosphere Dynamics. San Diego: Academic Press. 489

Ayarzaguena B, Serrano E. 2009. Monthly characterization of the tropospheric circulation over the Euro-Atlantic area in relation with the timing of stratospheric final warmings. J Clim, 22: 6313-6324

Baldwin M P, Dunkerton T J. 2001. Stratospheric harbingers of anomalous weather regimes. Science, 294: 581-584

Baldwin M P, Stephenson D B, Thompson D W J, et al. 2003. Stratospheric memory and skill of extended-range weather forecasts. Science, 301: 636-640

Black R X, McDaniel B A, Robinson W A. 2006. Stratosphere-troposphere coupling during spring onset. J Clim, 19: 4891-4901

Black R X, Mcdaniel B A. 2007a. The dynamics of Northern Hemisphere stratospheric final warming events. J Atmos Sci, 64: 2932-2946

Black R X, Mcdaniel B A. 2007b. Interannual variability in the Southern Hemisphere circulation organized by stratospheric final warming events. J Atmos Sci, 64: 2968-2974

Cai M, Ren R C. 2007. Meridional and downward propagation of atmospheric circulation anomalies. Part I: Northern Hemisphere cold season variability. J Atmos Sci, 64: 1880-1901

Charlton A J, Polvani L M. 2007. A new look at stratospheric sudden warmings. Part I: Climatology and modeling benchmarks. J Clim, 20: 449-469

Haigh J D, Roscoe H K. 2009. The final warming date of the Antarctic polar vortex and influences on its interannual variability. J Clim, 22: 5809-5819

Hardiman S C, Butchart N, Charlton-Perez A J, et al. 2011. Improved predictability of the troposphere using stratospheric final warmings. J Geophys Res, 116: D18113

Hu Y Y, Tung K K. 2002. Interannual and decadal variations of planetary wave activity, stratospheric cooling, and Northern Hemisphere annular mode. J Clim, 15: 1659-1673

Hu Y Y, Tung K K. 2003. Possible ozone-induced long-term changes in planetary wave activity in late winter. J Clim, 16: 3027-3038

Kanamttsu M, Ebisuzaki W, Woollen J, et al. 2002. NCEP-DOE AMIP-II Reanalysis (R-2). Bull Amer Meteorol Soc, 79: 61-78

Labitzke K, Naujokat B. 2000. The lower Arctic stratosphere in winter since 1952. SPARC Newletter, 15: 11-14 
Limpasuvan V, Thompson D W J, Hartmann D L. 2004. The life cycle of the Northern Hemisphere sudden stratospheric warmings. J Clim, 17: 2584-2596

Nash E R, Newman P A, Rosenfield J E, et al. 1996. An objective determination of the polar vortex using Ertel's potential vorticity. J Geophys Res, 101: 9471-9478

Ren R C, Cai M. 2007. Meridional and vertical out-of-phase relationships of temperature anomalies associated with the Northern Annular Mode variability. Geophys Res Lett, 34: L07704

Ren R C, Yang Y. 2012. Changes of the winter stratospheric circulation in CMIP5 scenarios simulated by the climate system model FGOALS-s2. Adv Atmos Sci, 29: 1374-1389

Shindell D T, Miller R L, Schmidt G A, et al. 1999. Simulation of recent northern winter climate trends by greenhouse-gas forcing. Nature, 399: 452-455

Shindell D T, Schmidt G A, Miller R L, et al. 2001. Northern Hemisphere winter climate response to greenhouse gas, ozone, solar, and volcanic forcing. J Geophys Res, 106: 7193-7210

Thompson D W J, Wallace J M. 1998. The Arctic Oscillation signature in the wintertime geopotential height and temperature fields. Geophys Res Lett, 25: 1297-1300

Waugh D W, Randel W J. 1999. Climatology of Arctic and Antarctic polar vortices using elliptical diagnostics. J Atmos Sci, 56: 1594-1613

Waugh D W, Randel W J, Pawson S, et al. 1999. Persistence of the lower stratospheric polar vortices. J Geophys Res, 104: 27191-27201

Waugh D W, Rong P P. 2002. Interannual variability in the decay of lower stratospheric Arctic vortices. J Meteorol Soc Jpn, 80: 997-1012

Zhou S T, Gelman M E, Miller A J, et al. 2000. An inter-hemisphere comparison of the persistent stratospheric polar vortex. Geophys Res Lett, 27: $1123-1126$ 